\title{
Patterns of morphometric variation among species of the genus Cicada (Hemiptera: Cicadidae) in the Mediterranean area
}

\author{
Paula Cristina SiMÕES and José Alberto QUARTAU
} Centro de Biologia Ambiental/Departamento de Biologia Animal, Bloco C2, $3^{\circ}$ Piso, Faculdade de Ciências de Lisboa,
Campo Grande, 1749-016 Lisboa, Portugal; e-mails: pcsimoes@fc.ul.pt, jaquartau@fc.ul.pt

Key words. Hemiptera, Cicada, morphology, morphometry, Portugal, Greece, Turkey

\begin{abstract}
Selected populations of five closely related species of the genus Cicada L. were collected mainly on the Portuguese, Greek and Turkish mainland, as well as on several Aegean islands. Ten morphometric traits of external structures and seven of male genitalia were analysed and the results revealed patterns in morphometric variation for each species. Only $C$. lodosi was always completely discriminated by both character sets and C. barbara by the male genitalia analysis. For the remaining species there was great overlap between the clusters. Body length, of the external morphological structures, and measurements of the pygophore, of the male genitalia, were the best variables for identifying $C$. lodosi and C. barbara. The present morphometric analyses revealed that divergence in morphology is much less pronounced than the divergence in acoustic signals and DNA. Thus, the congruence between morphological divergence, namely at the level of the external structures, and both behavioural (acoustic) and genetic divergence is quite low.
\end{abstract}

\section{INTRODUCTION}

Cicadas are Hemipteran insects usually recognised by the ability of males to produce loud airborne acoustic signals during pairing and courtship (e.g. Claridge, 1985; Boulard \& Mondon, 1995; Quartau, 1995). Females are only attracted to the calls of conspecific males, thus cicada acoustic signals are species specific (e.g. Claridge, 1985) and can be used, like taxonomic characters, to identify most species of cicada.

In practice it is usually not always possible to have live specimens and thus difficulties may arise in the identification of cicadas. On the other hand, in many instances, like in the genus Cicada Linnaeus, where the male calls of the different species are quite distinct, it is difficult to separate specimens only on the basis of their morphology. In fact, these cicadas form a complex of sibling species looking very similar on the basis of the external morphology and even the male genitalia. However, a few differences in structure and colour can be found, especially when large series of specimens are analysed (Quartau, 1988; Simões et al., 2000; Quartau \& Simões, 2006).

Five species occurring mainly on the Portuguese, Greek and Turkish mainland, as well as on several Aegean islands, were analysed in this study: Cicada barbara Stål 1866 (with the two subspecies C. b. barbara Stål 1866 and C. b. lusitanica Boulard 1982), C. cretensis Quartau \& Simões 2005, C. lodosi Boulard 1979, C. mordoganensis Boulard 1979 and C. orni Linnaeus 1755.

The objective of the present paper is to use a set of measurements of the external morphology and male genitalia to identify and quantify subtle differences between the five species in this complex and determine whether they are reproductively isolated (e.g. Claridge et al., 1997; Simon, 1992) by studying considerably more indi- viduals of each of the five species than Quartau (1988), who only studied $C$. orni and $C$. barbara. In particular, the phenetic (morphological) divergence will be assessed and compared with acoustic (Simões et al., 2000; Quartau \& Simões, 2006) and genetic data (Seabra et al., 2000; Quartau et al., 2000, 2001; Pinto-Juma, 2009).

\section{MATERIAL AND METHODS}

Males of the Cicada species were identified in the field by their songs, located and collected during the summers of 1996 to 2006 in the Mediterranean area. Specimens collected from populations of five species on the mainland as well as several islands were analysed (C. barbara, C. cretensis, C. lodosi, $C$. mordoganensis and C. orni) (Fig. 1; Table 1).

Based on previous results (e.g. Quartau \& Simões, 2006) it was decided to study two areas in particular: the first is located in the western part of the Mediterranean area (Iberian Peninsula and north-western Africa), where C. barbara and $C$. orni coexist. The second encompasses a larger assemblage of closely related species $-C$. cretensis, $C$. lodosi, C. orni and C. mordoganensis - and is located in the eastern part of the Mediterranean basin, and includes mainly the Balkans, the Aegean islands and Turkish mainland. Cicada permagna Haupt 1917 and $C$. cerisyi Guérin-Méneville 1844, two nominal species of doubtful affinities, which are reported from Turkey, and Egypt and Libya, respectively, were not considered.

In order to determine whether there are patterns in the variation in the size of the 10 morphological structures listed in Fig. 2 the measurements for a total of 316 males of five species (Table 1) were analyzed. The measurements were of external morphological structures (head and thorax including wings, and tymbals). In addition, a submatrix of measurements of seven traits of the male genitalia of 48 specimens was subjected to a morphometric analysis (Table 2 and Fig. 3). This analysis is of particular interest since some of the structures of the male genitalia are thought to be phylogenetically informative (e.g. Quartau, 1988; Claridge et al., 1997). Using a ruler the lengths of the body and wings were measured to the nearest $0.5 \mathrm{~mm}$. All the 


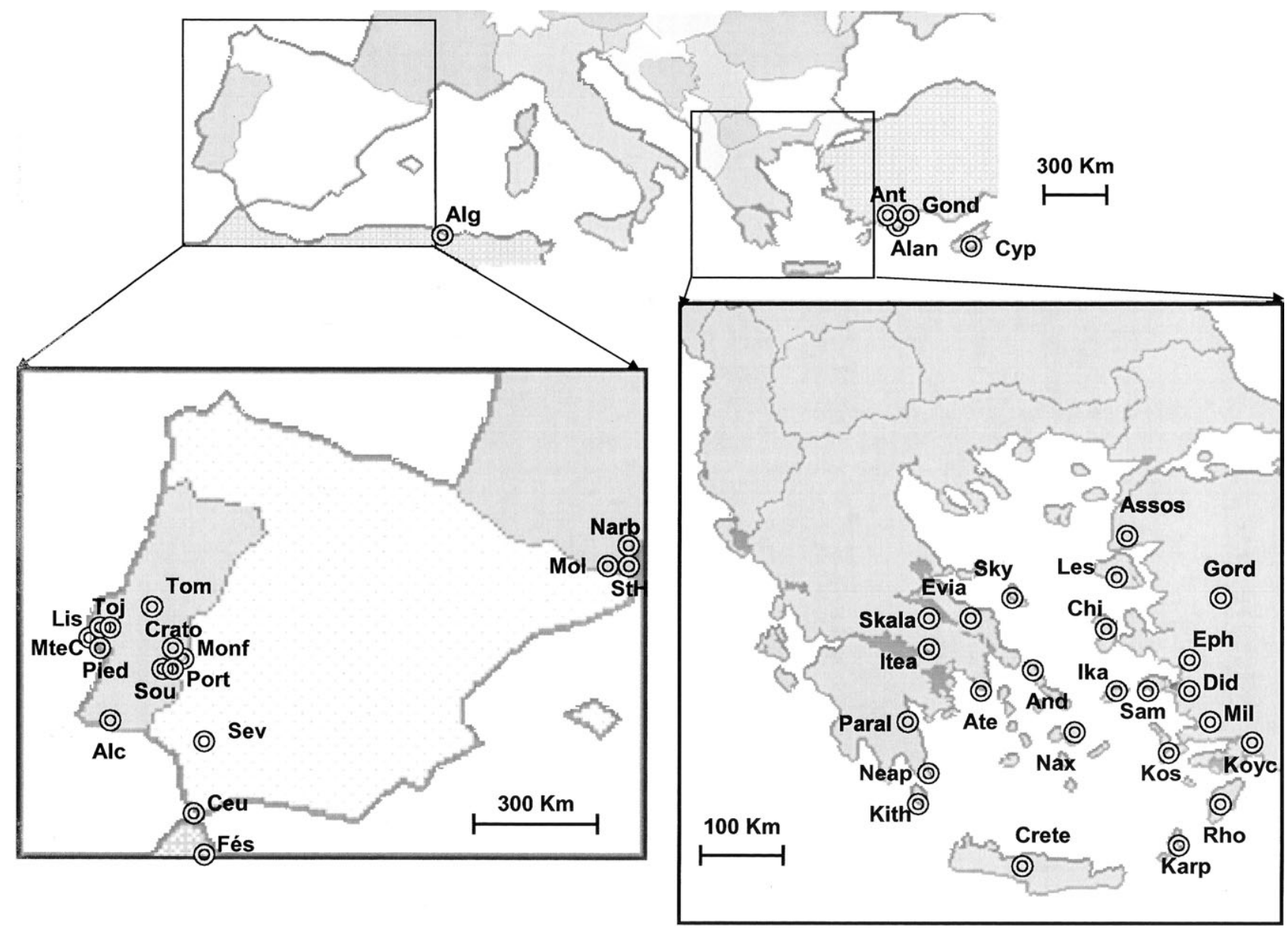

Fig. 1. Localities where the specimens of Cicada analysed were collected (for full names of abbreviations see Tables 1 and 2).

other measurements were made using a Wild M5 binocular microscope fitted with an ocular micrometer. Except for damaged specimens all measurements were made on the left side of each specimen. Each trait was measured twice and the measurements averaged.

Univariate analyses were used to estimate means and standard deviations, and minimum and maximum values. Nonparametric Kruskal-Wallis (KW) tests were used to compare the results for several independent samples of each trait, in addition to twosample comparisons using nonparametric Mann-Whitney $\underline{\mathrm{U}}$ (MW) tests. The significance level of the multiple tests was assessed by changing the critical $\mathrm{P}$ value obtained using the Dunn-Sidak method from $p<0.05$ to $1-(0.951)^{1 / k}$, where $\mathrm{k}$ is the number of tests (Dytham, 2003).

Discriminant Function Analysis (DFA) of both the measurements of external morphological structures and male genitalia was used to identify the statistically significant discriminant functions that separate the groups and determine how each discriminant function contributes to the discrimination between groups. Moreover, a R-type principal component analysis (PCA) was also performed on both data sets, and the Kaiser criterion used to determine the components with eigenvalues greater than one. Ultimately, the results chosen for presentation were those selected on the basis of the results of the above statistical tests.

Statistical procedures were performed using Statistica 8.0 software (Statsoft inc., Tulsa, USA).

\section{RESULTS}

The present paper is a comparative morphometric study of selected populations of five closely related species of the genus Cicada in the Mediterranean area. A total of 316 males were studied. Figs 4 and 6, and Tables 3 and 9 give a summary of the descriptive statistics of the morphometric features measured.

\section{External morphological traits}

As expected, C. lodosi proved to be the biggest species (male body length: $48-51 \mathrm{~mm}$ ) in all the morphometric features measured (cf. Fig. 4 and Table 3). In contrast, in terms of most of these features, C. orni and C. barbara were the smallest species (cf. Table 3 ). In addition, $C$. orni and $C$. mordoganensis were the most variable of the species (Fig. 4), which can be related to the fact that there were larger samples of these species.

Nonparametric Kruskal-Wallis tests showed that all variables differed significantly among the species $(p>$ $0.05)$.

In fact, the results of the Mann-Whitney $\underline{\mathrm{U}}$ tests, after applying the Dunn-Sidak correction, indicate that $C$. lodosi differs in all morphometric traits, with the exception of the antenna-eye distance, from the other species, and $C$. orni differs from $C$. cretensis in all traits except the length of rostrum, tymbal width and wing width. When compared with $C$. mordoganensis, it differed in 
TABLE 1. Number of specimens of each Cicada species used in the analysis of the variation in external morphology, with abbreviations for the localities from which they were collected (abbrev.).

\begin{tabular}{|c|c|c|c|c|c|c|c|}
\hline Locality & Abbrev. & $\begin{array}{c}\text { Cicada barbara } \\
\text { barbara }\end{array}$ & $\begin{array}{c}\text { Cicada barbara } \\
\text { lusitanica }\end{array}$ & $\begin{array}{c}\text { Cicada } \\
\text { cretensis }\end{array}$ & $\begin{array}{l}\text { Cicada } \\
\text { lodosi }\end{array}$ & $\begin{array}{c}\text { Cicada } \\
\text { mordoganensis }\end{array}$ & $\begin{array}{c}\text { Cicada } \\
\text { orni }\end{array}$ \\
\hline ALGERIA (Ziana) & Alg & 2 & & & & & \\
\hline CYPRUS & Cyp & & & & & & 5 \\
\hline \multicolumn{8}{|l|}{ PORTUGAL } \\
\hline Monforte (Alto Alentejo) & Monf & & & & & & 1 \\
\hline Sousel (Alto Alentejo) & Sou & & 6 & & & & 15 \\
\hline Crato (Alto Alentejo) & Crato & & 3 & & & & 1 \\
\hline Portel (Alto Alentejo) & Port & & & & & & 1 \\
\hline Lisboa (Estremadura) & Lis & & & & & & 1 \\
\hline Piedade (Arrábida, Estremadura) & Pied & & & & & & 1 \\
\hline Monte-da-Caparica (Estremadura) & MteC & & & & & & 11 \\
\hline S. Julião-do-Tojal (Estremadura) & Toj & & & & & & 15 \\
\hline \multicolumn{8}{|l|}{ SPAIN } \\
\hline Seville (Andalusia) & Sev & & 1 & & & & \\
\hline Ceuta & Ceu & & 3 & & & & \\
\hline \multicolumn{8}{|l|}{ FRANCE } \\
\hline $\begin{array}{l}\text { Molitg-les-Bains } \\
\text { (Languedoc-Roussillon) }\end{array}$ & Mol & & & & & & 2 \\
\hline St Hippolyte (Languedoc-Roussillon) & $\mathrm{StH}$ & & & & & & 10 \\
\hline Narbonne (Languedoc-Roussillon) & Narb & & & & & & 6 \\
\hline \multicolumn{8}{|l|}{ GREECE } \\
\hline Itea (Athika) & Itea & & & & & & 18 \\
\hline Skala (Athika) & Skala & & & & & & 1 \\
\hline Evia (Athika) & Evia & & & & & & 9 \\
\hline Athens (Athika) & Ate & & & & & & 6 \\
\hline Paralio (Peloponnese) & Paral & & & & & & 12 \\
\hline Neapolis (Peloponnese) & Neap & & & & & & 16 \\
\hline Skyros (Sporades) & Sky & & & & & & 14 \\
\hline Naxos (Cyclades) & Nax & & & & & & 14 \\
\hline Andros (Cyclades) & And & & & & & & 9 \\
\hline Lesbos (Northeastern Aegean sea) & Les & & & & & & 8 \\
\hline Kos (Dodecanese) & Kos & & & & & 14 & \\
\hline Rhodes (Dodecanese) & Rho & & & & & 2 & \\
\hline Chios (North Aegean sea) & Chi & & & & & 1 & \\
\hline Ikaria (eastern Aegean sea) & Ika & & & & & 11 & \\
\hline Samos (Eastern Aegean sea) & Sam & & & & & 7 & \\
\hline Crete (Southern Aegean sea) & Crete & & & 28 & & & \\
\hline Karpathos (Dodecanese) & Karp & & & 4 & & & \\
\hline Kithira (Ionian) & Kith & & & 19 & & & \\
\hline MOROCCO (Fés) & Fés & 5 & & & & & \\
\hline \multicolumn{8}{|l|}{ TURKEY } \\
\hline Assos (Ayvacyk) & Assos & & & & & & 2 \\
\hline Alanya (Antalya) & Alan & & & & 1 & & \\
\hline Gundogmus (Antalya) & Gond & & & & 1 & & \\
\hline Koycegiz (Mugla) & Koyc & & & & 1 & 8 & \\
\hline Gordes (Manisa) & Gord & & & & 2 & & \\
\hline Antalya (Antalya) & Ant & & & & & 3 & \\
\hline Milas (Mugla) & Mil & & & & & 3 & \\
\hline Didim (Aydim) & Did & & & & & 9 & \\
\hline Ephesus (Izmir) & Eph & & & & & 4 & \\
\hline
\end{tabular}

every trait except front length, tymbal width and tymbal length. It had fewer significant differences when compared with $C$. barbara (differed in head width, pronotum width, front length, antenna-eye distance, length of rostrum and tymbal length). Likewise, C. mordoganensis differed in few traits when compared with $C$. cretensis (front length and length of rostrum). Moreover, in terms of all the traits, Cicada barbara barbara and Cicada barbara lusitanica did not differ significantly.

When comparing specimens from different geographical areas (Portugal, France, Greece, Turkey and Cyprus) after applying the Dunn-Sidak correction, males of C. orni from some pairs of areas differed. Nonetheless, the eastern Mediterranean populations studied (from 

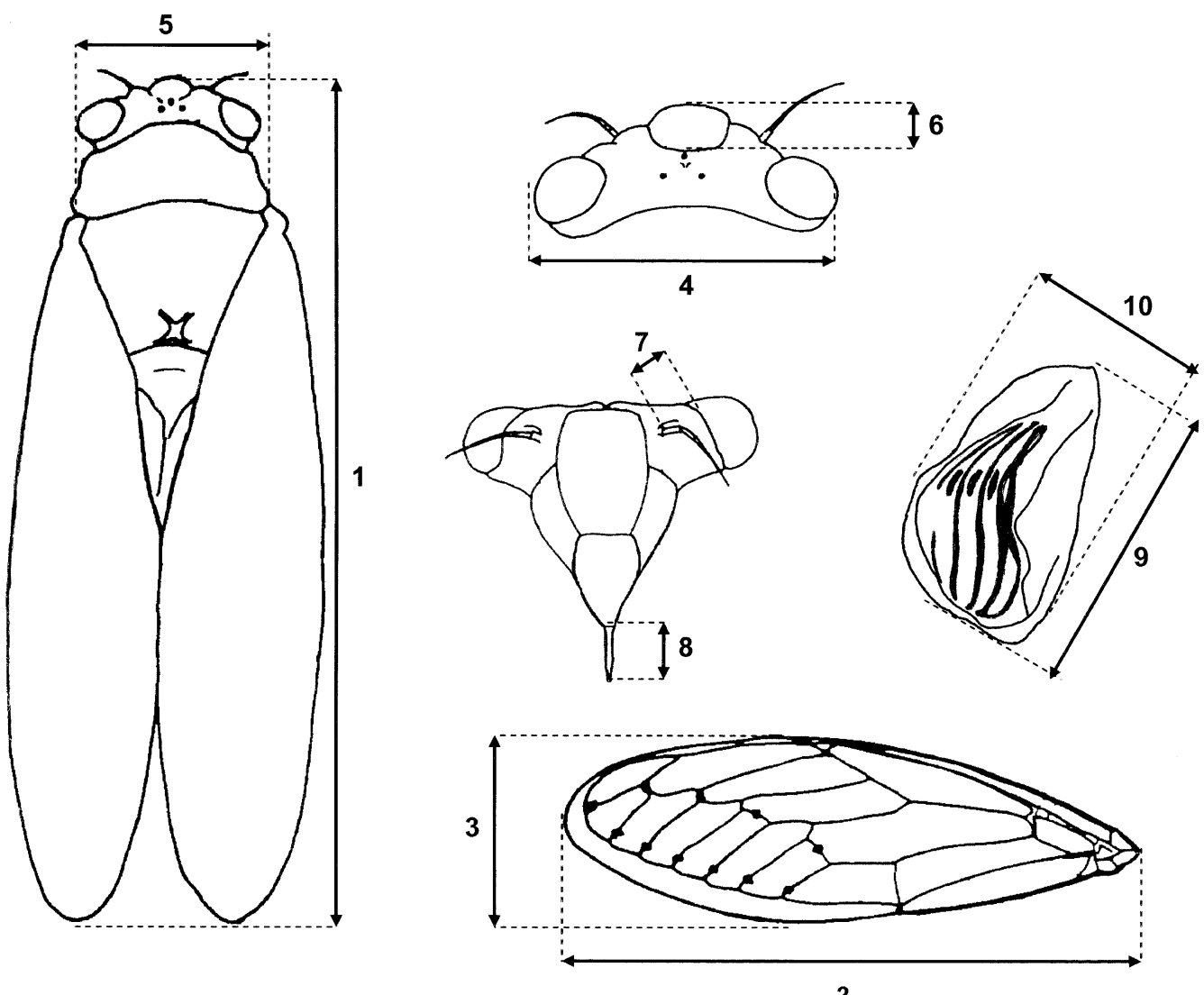

2

Fig. 2. Measurements of external morphology of the five species of Cicada studied (different scales). 1 - body length (overall body length from tip of the head to the end of the wings in resting position); 2 - forewing length (distance from base of left forewing articulation to tip of wing); 3 - forewing width (greatest width of left forewing); 4 - head width (maximum head width measured between exterior eye margins); 5 - pronotum width (maximum width of pronotal collar); 6 - front length (length of the front measured along the dorsal median line); 7 - antenna-eye distance (distance between the base of the left antenna and the left ocular suture); 8 - rostrum length; 9 - tymbal length (overall length of left tymbal); 10 - tymbal width (greatest width of left tymbal ).

TABLE 2. Number of specimens of each Cicada species used in the analysis of the variation in male genitalia, with abbreviations for the localities where they were collected (Abbrev.).

\begin{tabular}{|c|c|c|c|c|c|c|c|}
\hline Locality & Abbrev. & $\begin{array}{c}\text { Cicada barbara } \\
\text { barbara }\end{array}$ & $\begin{array}{c}\text { Cicada barbara } \\
\text { lusitanica }\end{array}$ & $\begin{array}{c}\text { Cicada } \\
\text { cretensis }\end{array}$ & $\begin{array}{l}\text { Cicada } \\
\text { lodosi }\end{array}$ & $\begin{array}{c}\text { Cicada } \\
\text { mordoganensis }\end{array}$ & $\begin{array}{c}\text { Cicada } \\
\text { orni }\end{array}$ \\
\hline \multicolumn{8}{|l|}{ PORTUGAL } \\
\hline Monforte (Alto Alentejo) & Monf & & & & & & 3 \\
\hline Crato (Alto Alentejo) & Crato & & 3 & & & & \\
\hline Alcalar (Alarve) & Alc & & 3 & & & & \\
\hline Tomar (Estremadura) & Tom & & & & & & 3 \\
\hline \multicolumn{8}{|l|}{ SPAIN } \\
\hline Ceuta & $\mathrm{Ceu}$ & & 3 & & & & \\
\hline \multicolumn{8}{|l|}{ GREECE } \\
\hline Athens (Athika) & Ate & & & & & & 3 \\
\hline Skyros (Sporades) & Sky & & & & & & 3 \\
\hline Lesbos (Northeastern Aegean sea) & Les & & & & & & 3 \\
\hline Kos (Dodecanese) & Kos & & & & & 3 & \\
\hline Rhodes (Dodecanese) & Rho & & & & & 3 & \\
\hline Samos (Eastern Aegean sea) & Sam & & & & & 3 & \\
\hline Crete (Southern Aegean sea) & Crete & & & 3 & & & \\
\hline Kithira (Ionian) & Kith & & & 3 & & & \\
\hline MOROCCO (Fés) & Fés & 3 & & & & & \\
\hline \multicolumn{8}{|l|}{ TURKEY } \\
\hline Gondogmus (Antalya) & Gond & & & & 1 & & \\
\hline Gordes (Manisa) & Gord & & & & 2 & & \\
\hline Milas (Mugla) & Mil & & & & & 1 & \\
\hline Didim (Aydim) & Did & & & & & 2 & \\
\hline
\end{tabular}




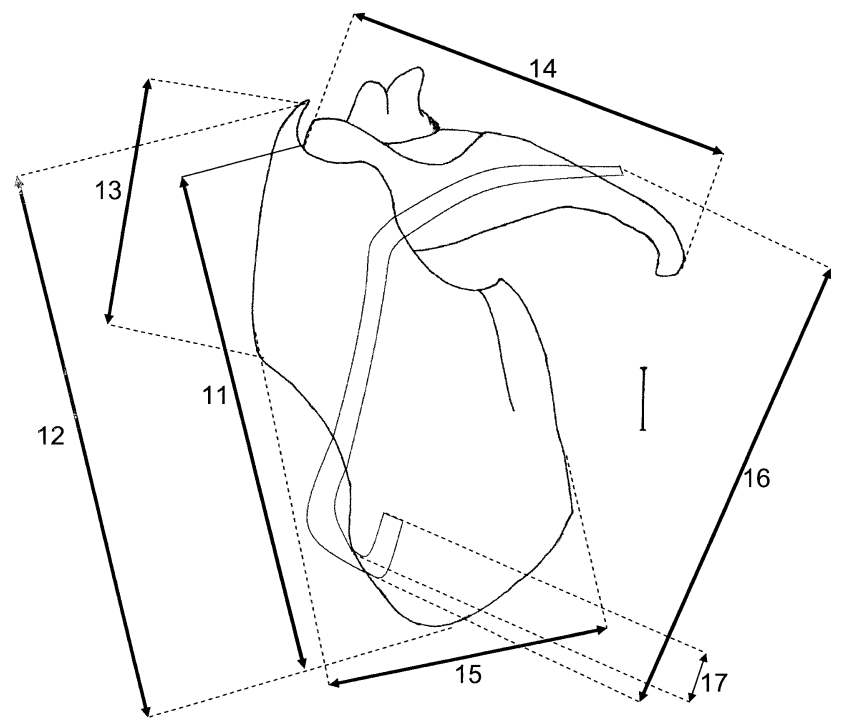

Fig. 3. Measurements of male genitalia of the five species of Cicada studied (illustrated C. cretensis; scale $=0.05 \mathrm{~mm}$ ). 11 pygophore length without spine (length of pygophore from the anterior side to the base of the small apical spine in left lateral view); 12 - overall pygophore length (overall length of pygophore in left lateral view); 13 - pygophore posterior length (length of dorsal posterior side of pygophore); $14-10^{\text {th }}$ abdominal segment length (overall length of $10^{\text {th }}$ abdominal segment in left lateral view); 15 - pygophore width (maximum width of pygophore in left lateral view); 16 - aedeagus length; 17 - aedeagus apodeme length (length of basal apodeme of aedeagus).

Cyprus, Turkey and Greece) did not differ significantly from each other. In contrast, specimens from Portugal differed more from those from all the other areas, particularly the Greek specimens (differed in all morphometric traits except forewing width and antenna-eye distance). Portuguese specimens also differed from the French ones in body length, wing width, wing length and tymbal length, and the French specimens from the Greek ones in front length, tymbal length and tymbal width.

Discriminant function analysis of the ten morphometric traits of the species studied revealed that they differed statistically significantly in more of the traits than revealed by PCA (except for forewing length and tymbal width)
(Table 4). Body length, front length and length of rostrum were the variables with the lowest partial Wilks' lambda values $(0.819,0.817$ and 0.681 , respectively), and therefore the best characters for discriminating between groups (Table 4).

Classification functions were significant for $C$. lodosi $(p=0.016), C . b$. barbara $(p=0.022)$ and $C$. b. lusitanica $(p=0.041)$ (Table 5). C. lodosi clustered mainly on the basis of its body length, while rostrum length, head width and body length were the most important traits for the clustering of the two subspecies of C. barbara.

Overall $81 \%$ of the classifications were correctly attributed (Table 6). All C. lodosi specimens were correctly attributed and for the remaining species it was $88 \%$ for $C$. orni, $76 \%$ for C. mordoganensis, $68 \%$ for C. cretensis, $69 \%$ for C. b. lusitanica and $43 \%$ for C. b. barbara.

The first and second roots of the canonical variables extracted eigenvalues of 1.58 and of 0.66 , respectively (Table 7) and were mainly marked by negative coefficients for body length $(-1.300)$ and rostrum length $(-0.951)$. Root 1 discriminated mainly $C$. lodosi from all the remaining species, while root 2 was not particularly helpful in discriminating any species (Fig. 5, Table 8).

For most species except $C$. lodosi (Fig. 5), there were no clear-cut clusters, in spite of some clear trends in variation. C. barbara specimens are in the up-right quadrant but overlap some $C$. orni specimens (identified as from Portel, Molitg and Narbonne but not shown). On the other hand, most specimens of $C$. cretensis form a uniform cluster partially overlapping, however, C. orni and C. mordoganensis.

Moreover, C. mordoganensis and C. orni tended to cluster separately, overlapping in the middle. Noteworthy is that the specimens of $C$. mordoganensis from Turkey (not shown in Fig. 5) form a quite homogeneous group with little overlap with the remaining species.

In contrast, males of $C$. orni from several of the localities in western and south-eastern Europe clustered as a quite heterogeneous group (not shown in 5), with the French males forming a more or less consistent group closer to those of $C$. barbara (not represented) than those of $C$. cretensis and C. mordoganensis.

TABLE 3. Descriptive statistics of the measurements (in mm) of 10 external morphological traits of the species of Cicada studied.

\begin{tabular}{|c|c|c|c|c|c|c|c|c|c|c|c|c|c|c|c|c|c|c|c|c|c|c|c|c|}
\hline \multirow[b]{2}{*}{ Trait } & \multicolumn{4}{|c|}{$\begin{array}{c}\text { C. barbara } \\
\text { lusitanica }(\mathrm{N}=13)\end{array}$} & \multicolumn{4}{|c|}{$\begin{array}{c}\text { C. barbara } \\
\text { barbara }(\mathrm{N}=7)\end{array}$} & \multicolumn{4}{|c|}{$\begin{array}{l}\text { C. cretensis } \\
(\mathrm{N}=51)\end{array}$} & \multicolumn{4}{|c|}{ C. $\operatorname{lodosi}(\mathrm{N}=5)$} & \multicolumn{4}{|c|}{$\begin{array}{l}\text { C. mordoganensis } \\
(\mathrm{N}=62)\end{array}$} & \multicolumn{4}{|c|}{ C. orni $(\mathrm{N}=178)$} \\
\hline & & $M$ & $\mathrm{Ma}$ & $\begin{array}{c}\text { S. } \\
\text { Dev. }\end{array}$ & & & Max & $\begin{array}{c}\text { S. } \\
\text { Dev. }\end{array}$ & $\mathrm{Me}$ & & $\mathrm{M}$ & $\begin{array}{c}\text { S. } \\
\text { Dev. }\end{array}$ & & & & $\begin{array}{c}\text { S. } \\
\text { Dev. }\end{array}$ & & & Max & $\begin{array}{c}\text { S. } \\
\text { Dev. }\end{array}$ & & & & $\begin{array}{c}\text { S. } \\
\text { Dev }\end{array}$ \\
\hline & & & & 1.3 & 38 & & 39.0 & 0.2 & & & 46.0 & 2.0 & & & & 1.3 & & & 46.0 & 2.2 & & & & 2.4 \\
\hline & & & & 1.2 & & & & 0.2 & & & & 1.5 & & & & 1.5 & & & & 1.8 & & & & 2.2 \\
\hline & & & & 0.5 & & & & 0.8 & & 9.0 & & 0.7 & & & & 0.4 & 11.2 & 9.5 & 13.0 & 0.7 & 10.6 & 8.5 & 12.0 & 0.8 \\
\hline & & 8.3 & 9.4 & 0.3 & & 8.7 & 9.0 & 0.1 & & 7.8 & 9.6 & 0.4 & 9.4 & 8.9 & 9.1 & 0.3 & 8.6 & 4.1 & 10.1 & 0.7 & 8.4 & 7.3 & 9.5 & 0.5 \\
\hline & & 9.2 & 10.4 & 0.5 & 9.7 & 9.3 & 10.2 & 0.3 & 10.1 & 8.8 & 11.3 & 0.5 & 10.8 & 10.0 & 11.1 & 0.4 & 9.9 & 8.1 & 11.0 & 0.6 & 9.5 & 7.7 & 10.8 & 0.6 \\
\hline & & 1.1 & 1.5 & 0.1 & & & 1.3 & 0.1 & & 0.9 & 1.5 & 0.1 & 1.5 & & & 0.1 & 1.1 & 0.8 & 1.3 & 0.1 & & 0.8 & 1.4 & 0.1 \\
\hline & & 1.2 & 1.4 & 0.1 & 1.2 & & 1.3 & 0.0 & & 1.0 & & 0.1 & 1.2 & 1.1 & & 0.1 & & 1.0 & 1.4 & 0.1 & 1.2 & 1.0 & 1.4 & 0.1 \\
\hline & & 8.5 & 9.6 & 0.4 & 8.5 & 8.2 & 9.0 & 0.2 & 9.4 & 8.4 & 10.4 & 0.4 & 11.0 & 10.6 & 611.4 & 0.3 & 10.0 & 8.0 & 11.1 & 0.6 & 9.2 & 6.3 & 10.4 & 0.6 \\
\hline & & 3.9 & 4.8 & 0.3 & 4.7 & 4.0 & 4.9 & 0.1 & 5.0 & 3.2 & 5.7 & 0.4 & 5.3 & 5.2 & 5.5 & 0.2 & 4.9 & 4.2 & 5.4 & 0.3 & 4.8 & 4.0 & 5.4 & 0.3 \\
\hline Tymbal width & 2.5 & 2.2 & 2.7 & 0.1 & 2.4 & 2.3 & 2.6 & 0.1 & 2.5 & 2.3 & 2.9 & 0.1 & 2.7 & 2.6 & 2.7 & 0.1 & 2.5 & 2.1 & 2.7 & 0.1 & 2.4 & 2.0 & 3.3 & 0.2 \\
\hline
\end{tabular}



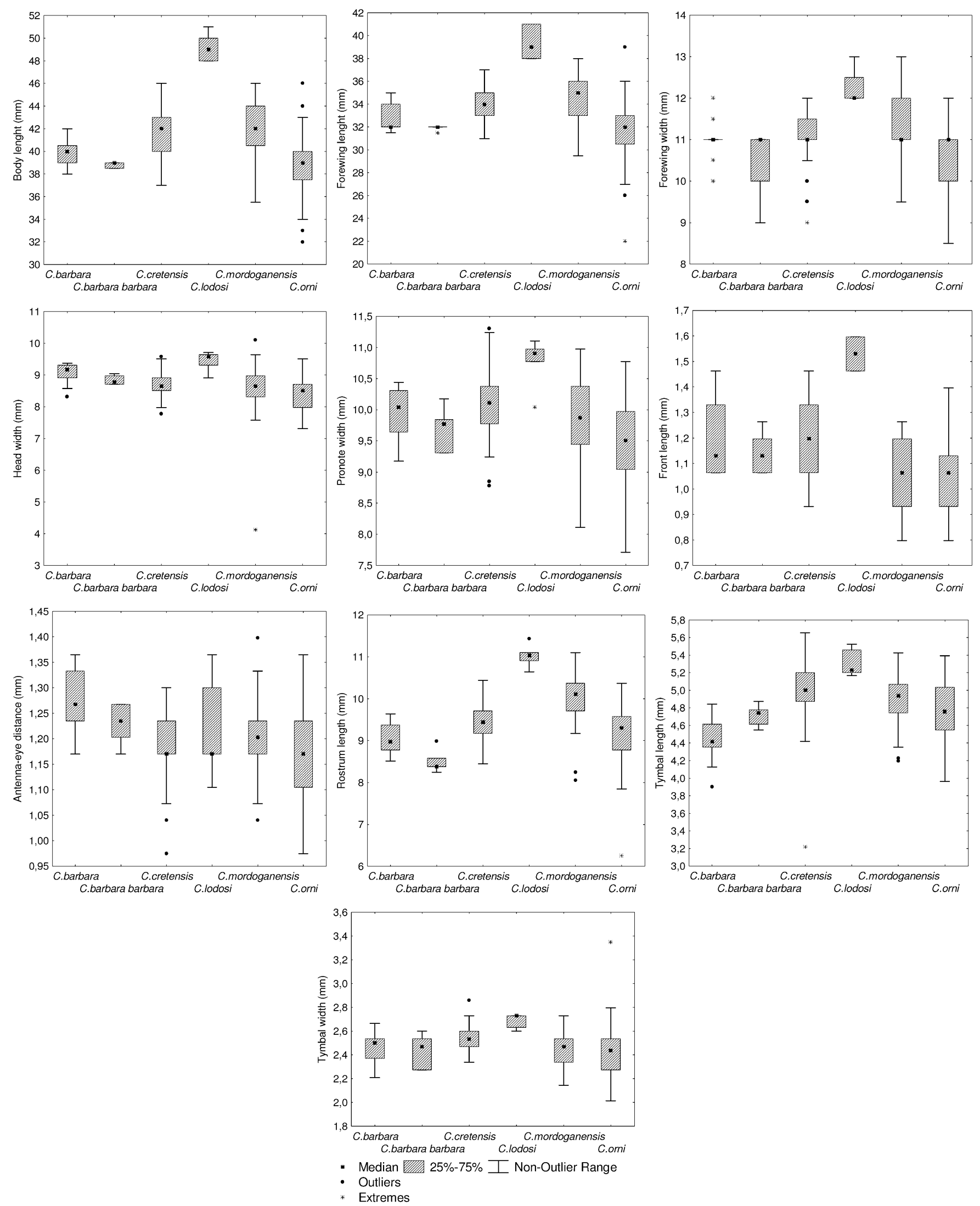

Fig. 4. Box and whisker plots comparing the measurements of 10 external morphological features for each of the species of Cicada studied. (Non-outlier range - values below the upper outlier limit and above the lower outlier limit; Ouliers - values outside 1.5 box length range from the upper and lower value of the box; Extremes - values outside 3 box length range from the upper and lower value of the box). 


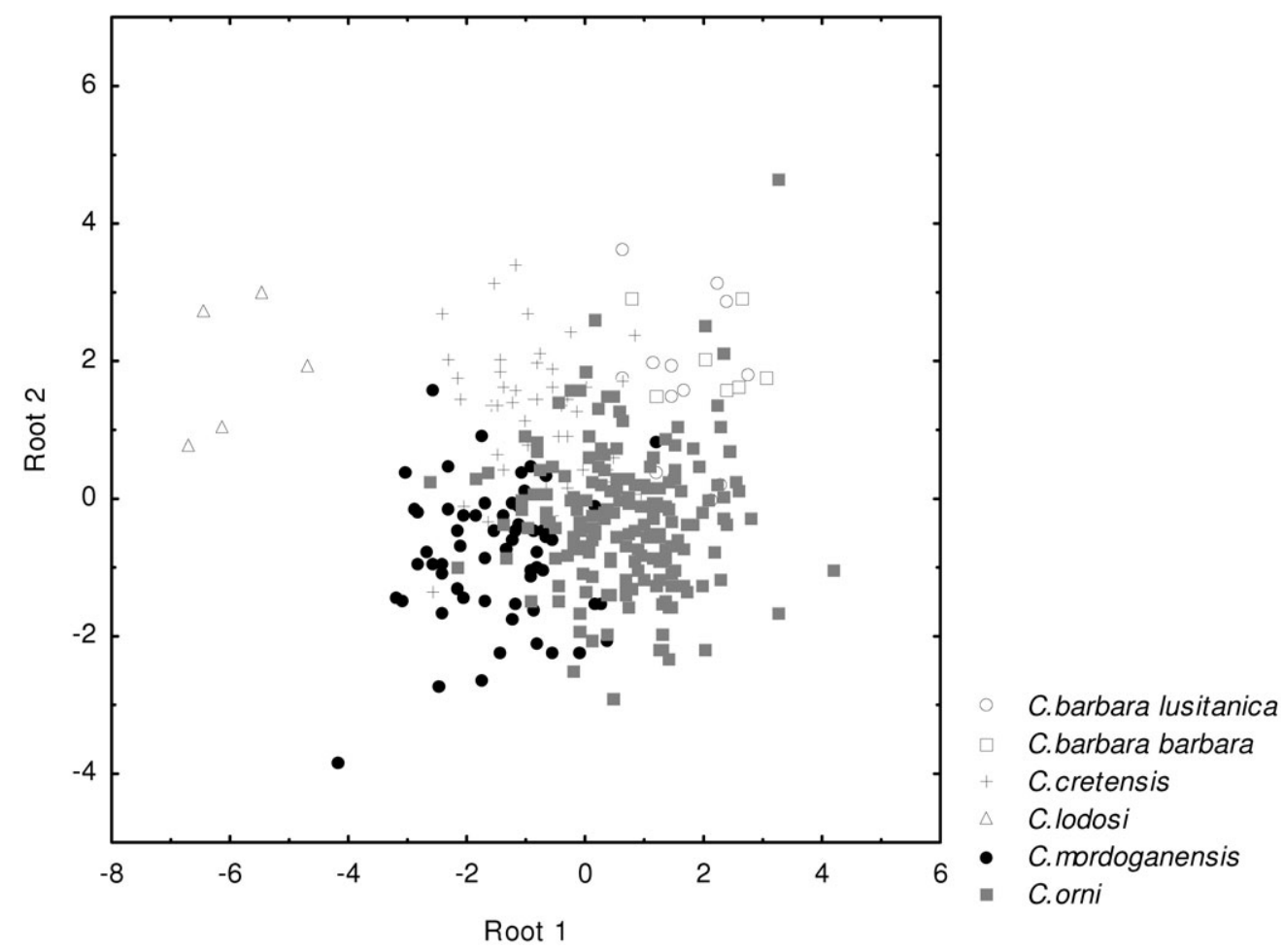

Fig. 5. Scatter-plot of the results of a canonical analysis based on discriminant functions of the 10 external morphological features of the species of Cicada studied (316 OTUs).

\section{Male genitalia}

The analyses of the male genitalia, Fig. 6 and Table 9, compared the seven variables for each of the species investigated. The specimens of $C$. barbara had lower values for the majority of the traits considered. In contrast, males of $C$. lodosi had higher values. The remaining three species had similar values.

MW tests performed with the Dunn-Sidak correction did not reveal any significant differences between pairs of species.

Principal component analysis gave better results than DFA and the resulting two dimensional diagram of the relationships between species is shown in Fig. 7. The first two components accounted for $77.9 \%$ of the total variation and more than half $(65.3 \%)$ of the variation was explained by the 1 st component. When plotting compo- nents 1 and 2, the distribution of most of the species along the $1^{\text {st }}$ axis is noteworthy. C. lodosi forms a clearly separated cluster in the upper left quadrant, similarly to what happened with the two subspecies of $C$. barbara in the right quadrant (Fig. 7). In this plot there is some separation of $C$. cretensis and $C$. orni, which overlap considerably with $C$. mordoganensis.

Factor loadings were high (Table 10) for the majority of the variables and as component 1 had the highest loadings for most of pygophore related traits, this was the structure that contributed most to the discrimination among the Cicada species studied.

\section{DISCUSSION AND CONCLUSIONS}

Previous studies on external morphology have shown that it is possible to recognise some general trends in each

TABLE 4. Summary of the Discriminant Function Analysis of the measurements of 10 external morphological traits of the species of Cicada studied (Wilks' Lambda $=0.15973, \mathrm{~F}(50.1376)=13.626 p<0.0001$ ).

\begin{tabular}{lcccccc}
\hline Trait & Wilks' & Partial & F-remove & p-level & Toler. & 1-Toler. \\
\hline Body length & 0.195 & 0.819 & 13.273 & 0.000 & 0.166 & 0.834 \\
Forewing length & 0.166 & 0.965 & 2.183 & 0.056 & 0.240 & 0.760 \\
Forewing width & 0.182 & 0.878 & 8.371 & 0.000 & 0.329 & 0.671 \\
Head width & 0.179 & 0.891 & 7.402 & 0.000 & 0.367 & 0.633 \\
Pronotum width & 0.172 & 0.928 & 4.680 & 0.000 & 0.262 & 0.738 \\
Front length & 0.196 & 0.817 & 13.487 & 0.000 & 0.857 & 0.143 \\
Antenna-eye distance & 0.181 & 0.881 & 8.161 & 0.000 & 0.600 & 0.400 \\
Rostrum lengh & 0.234 & 0.681 & 28.171 & 0.000 & 0.509 & 0.491 \\
Tymbal length & 0.183 & 0.875 & 8.605 & 0.000 & 0.560 & 0.440 \\
Tymbal width & 0.162 & 0.988 & 0.760 & 0.580 & 0.627 & 0.373 \\
\hline
\end{tabular}



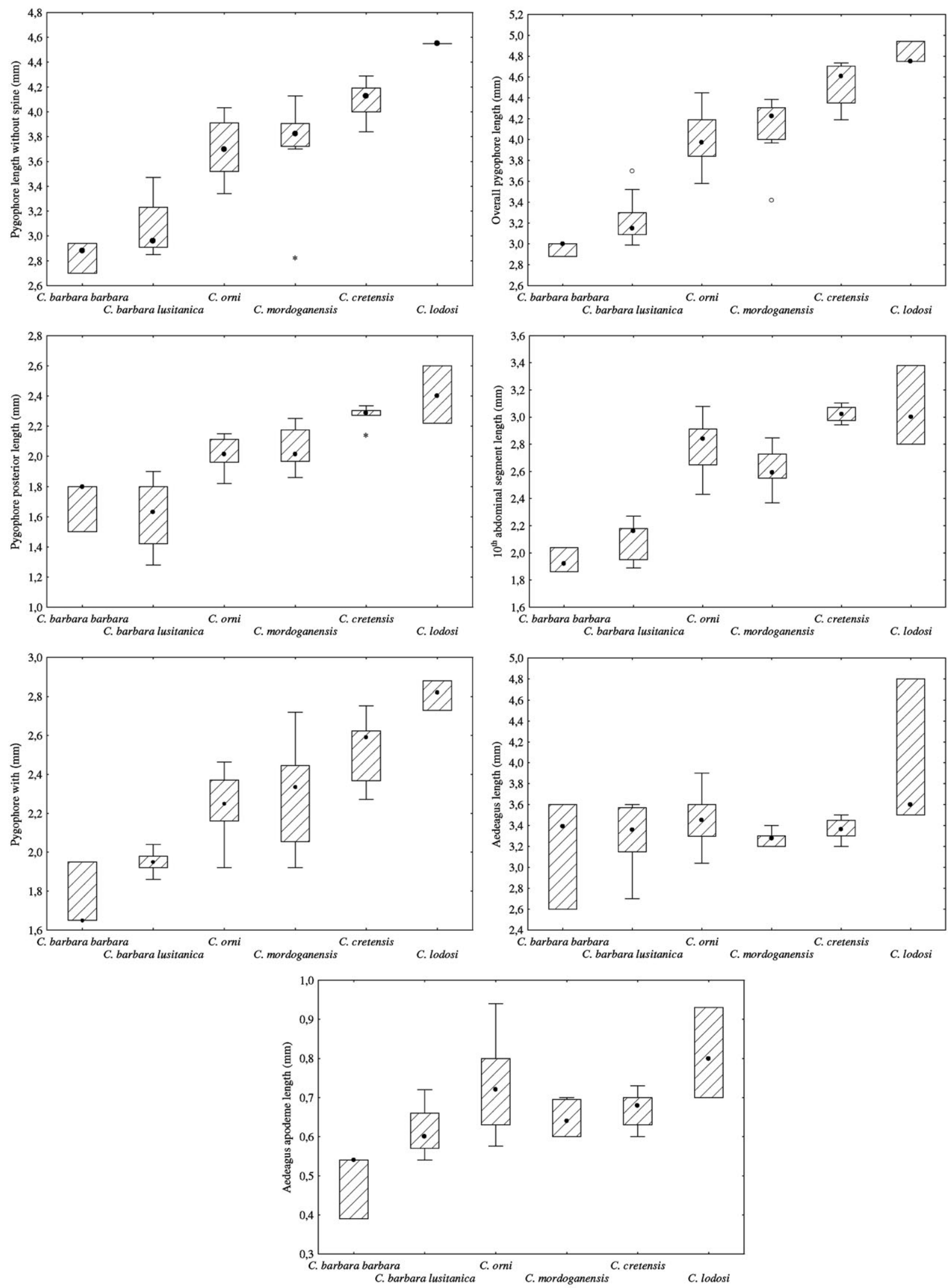

- Median $\oslash 25 \%-75 \%$ I Non-Outlier Range $\quad \circ$ Outliers $\quad *$ Extremes

Fig. 6. Box and whisker plots comparing the measurements of seven structures of the male genitalia of each of the species of Cicada studied (Non-outlier range - values below the upper outlier limit and above the lower outlier limit; Ouliers -values outside 1.5 box length range from the upper and lower value of the box; Extremes - values outside 3 box length range from the upper and lower value of the box). 


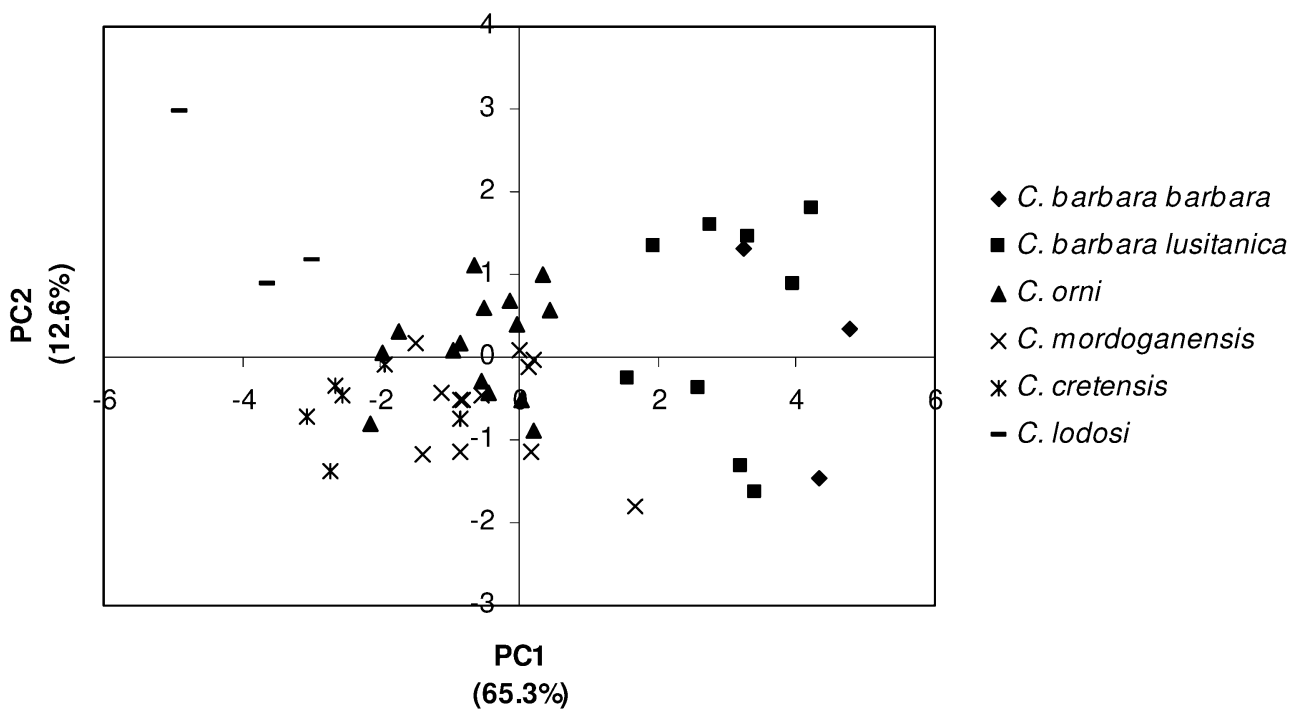

Fig. 7. Scatter-plot of the results of a principal component analysis based on a correlation matrix of the measurements of seven structures of the male genitalia of the species of Cicada studied (48 OTUs).

of the Cicada species, however there is considerable overlap between species. Thus, when considering individual specimens it is difficult to make a correct identification (e.g. Quartau \& Simões, 2006). Our previous experience indicated that is particularly difficult to discriminate between $C$. orni, C. cretensis and $C$. mordoganensis.

The present results strongly support the impression based on intuitive analyses (Quartau \& Simões, 2006). In fact, all species showed a typical pattern of morphometric variation. However, with the exception of $C$. lodosi, the analyses based on external morphology did not completely discriminate between any species or populations, with a general overlap among species being the rule. Body length, representing size, was the most important morphometric trait allowing some discrimination and classification, namely for $C$. lodosi, the biggest species. Moreover, C. b. barbara and C. b. lusitanica were also fairly well discriminated on the bases of their body and rostrum lengths.

The analysis based on male genitalia traits discriminated the species better than that based on external mor-

TABLE 5. Classification functions of the discriminant analysis conducted on the measurements of 10 external morphological traits of the species of Cicada studied.

\begin{tabular}{|c|c|c|c|c|c|c|}
\hline Trait & $\begin{array}{c}\text { C. barbara lusitanica } \\
p=0.04114\end{array}$ & $\begin{array}{c}\text { C. barbara barbara } \\
p=0.02215\end{array}$ & $\begin{array}{l}\text { C. cretensis } \\
p=0.14873\end{array}$ & $\begin{array}{c}\text { C. lodosi } \\
p=0.01582\end{array}$ & $\begin{array}{c}\text { C. mordoganensis } \\
p=0.19620\end{array}$ & $\begin{array}{c}\text { C. orni } \\
p=0.57595\end{array}$ \\
\hline Body length & -2.634 & -2.347 & 1.573 & 11.825 & 2.095 & -1.166 \\
\hline Forewing length & 0.739 & 0.910 & 0.977 & 0.174 & 0.380 & -0.474 \\
\hline Forewing width & 1.336 & -0.596 & -1.523 & -3.698 & -0.413 & 0.563 \\
\hline Head width & 2.427 & 2.582 & -0.705 & -1.025 & -0.831 & 0.221 \\
\hline Pronotum width & 0.245 & 0.626 & 1.126 & -3.286 & -0.723 & 0.004 \\
\hline Front length & 0.592 & 0.427 & 0.890 & 4.105 & -0.455 & -0.246 \\
\hline Antenna-eye distance & 2.018 & 1.770 & -0.421 & -2.796 & -0.511 & 0.148 \\
\hline Rostrum length & -2.423 & -4.231 & -1.092 & 3.057 & 2.113 & -0.186 \\
\hline Tymbal length & -2.464 & -0.150 & 0.359 & 0.084 & -0.395 & 0.221 \\
\hline Tymbal width & -0.014 & 0.050 & 0.345 & -0.332 & -0.238 & 0.000 \\
\hline
\end{tabular}

TABLE 6. Classification matrix of the discriminant analysis of the measurements of 10 external morphological traits of the species of Cicada studied. Rows: observed classification. Columns: predicted classification.

\begin{tabular}{lrrrrrrr}
\hline & Percentage & $\begin{array}{c}\text { C. barbara } \\
\text { lusitanica }\end{array}$ & $\begin{array}{c}\text { C. barbara } \\
\text { barbara }\end{array}$ & C. cretensis & C. lodosi & $\begin{array}{c}\text { C. mordo- } \\
\text { ganensis }\end{array}$ & C. orni \\
\hline C. barbara lusitanica & 69.231 & 9.000 & 1.000 & 0.000 & 0.000 & 0.000 & 3.000 \\
C. barbara barbara & 42.857 & 2.000 & 3.000 & 1.000 & 0.000 & 0.000 & 1.000 \\
C. cretensis & 68.085 & 1.000 & 0.000 & 32.000 & 0.000 & 3.000 & 11.000 \\
C. lodosi & 100.000 & 0.000 & 0.000 & 0.000 & 5.000 & 0.000 & 0.000 \\
C. mordoganensis & 75.806 & 0.000 & 0.000 & 1.000 & 0.000 & 47.000 & 14.000 \\
C. orni & 88.462 & 3.000 & 1.000 & 6.000 & 0.000 & 11.000 & 161.000 \\
\hline Total & 81.329 & 15.000 & 5.000 & 40.000 & 5.000 & 61.000 & 190.000
\end{tabular}


TABLE 7. Standardized coefficients for canonical variables based on discriminant functions of the measurements of 10 external morphological traits of the species of Cicada studied.

\begin{tabular}{lccccc}
\hline & Root 1 & Root 2 & Root 3 & Root 4 & Root 5 \\
\hline Body length & -1.300 & 0.255 & -0.053 & 0.439 & 0.666 \\
Forewing length & -0.173 & 0.351 & 0.160 & -0.891 & 0.092 \\
Forewing width & 0.561 & -0.502 & 0.446 & 0.444 & -0.840 \\
Head width & 0.477 & 0.310 & 0.583 & 0.530 & 0.911 \\
Pronotum width & 0.248 & 0.366 & -0.502 & -1.065 & -1.030 \\
Front length & -0.220 & 0.602 & -0.081 & 0.633 & -0.244 \\
Antenna-eye distance & 0.457 & 0.164 & 0.478 & -0.271 & 0.244 \\
Rostrum length & -0.626 & -0.951 & 0.270 & 0.309 & -0.193 \\
Tymbal length & -0.016 & -0.110 & -0.952 & 0.228 & 0.516 \\
Tymbal width & 0.036 & 0.133 & -0.183 & -0.141 & -0.348 \\
Eigenvalue & 1.580 & 0.664 & 0.298 & 0.101 & 0.021 \\
Cum. Prop. & 0.593 & 0.842 & 0.954 & 0.992 & 1.000 \\
\hline
\end{tabular}

phology. In fact, it gave a good separation of both $C$. lodosi and C. barbara and to a lesser extent of $C$. cretensis. As indicated above, the pygophore proved to be the structure that contributed most to this discrimination.

It should be noted that the calling songs of $C$. lodosi and $C$. barbara are continuous while those of the other species are discontinuous, consisting of echemes of different duration, separated by silent intervals. In fact, the species that show the greatest morphological divergence (C. lodosi and C. barbara) are the ones with the greatest acoustic and genetic divergences (Quartau et al., 2000, 2001; Quartau \& Simões, 2006; Pinto-Juma, 2009). Therefore, the present results resemble those obtained from acoustic and genetic analyses.

On the other hand, the pronounced morphometric differences between the populations of $C$. orni from the eastern and the western Mediterranean (MW tests and results not shown in Fig. 5) correlate with the acoustic data (Pinto-Juma et al., 2005). In the absence of samples from intermediate areas other than a few localities in France it is not possible to establish whether there is a cline from west to east.

The present results clearly corroborate previous studies (Quartau \& Simões, 2006), showing that in this complex of species the acoustic divergence observed in the calling songs is associated with low levels of morphological differentiation, especially in external morphology. Recent bioacoustic investigations have shown a similar pattern of
TABLE 8. Means of canonical variables based on discriminant functions of the measurements of 10 external morphological traits of the species of Cicada studied.

\begin{tabular}{lccccc}
\hline & Root 1 & Root 2 & Root 3 & Root 4 & Root 5 \\
\hline C. barbara lusitanica & 1.650 & 1.620 & 2.055 & 0.006 & -0.251 \\
C. barbara barbara & 2.103 & 2.046 & 0.262 & -0.275 & 0.837 \\
C. cretensis & 0.829 & 1.211 & -0.616 & -0.349 & 0.101 \\
C. lodosi & -5.887 & 1.907 & 0.303 & 1.807 & 0.142 \\
C. mordoganensis & -1.470 & -0.807 & 0.468 & -0.280 & 0.058 \\
C. orni & 0.678 & -0.285 & -0.165 & 0.146 & -0.012 \\
\hline
\end{tabular}

divergence in other groups of cicadas. This is the case for Cicadetta montana Scopoli 1772, a complex of morphologically similar European species, which are also best characterized by their calling songs (e.g., Gogala \& Trilar, 2004; Hertach, 2007; Sueur \& Puissant, 2007; Gogala et al., 2008).

However, it is interesting to note that this trend is not general for cicadas. For instance, in the case of the genus Tibicina Amyot, conspicuous morphological divergence is associated with very subtle acoustic differentiation (Quartau \& Simões, 2003; Sueur \& Aubin, 2003).

Hence, the calling song of the genus Cicada not only plays a role in long range attraction but also in short range communication, which is important in specific mate recognition (Paterson, 1985), as previous data suggested. This is possibly the reason why the divergence in morphology in these cicadas is less pronounced than the divergence in their acoustic signals, the latter being greater in sympatric species. In fact, $C$. lodosi can be sympatric with $C$. mordoganensis, while C. barbara lusitanica can either be allopatric or sympatric with $C$. orni (Sueur et al., 2004; Quartau \& Simões, 2006). On the other hand C. orni, C. mordoganensis and C. cretensis do not occur sympatrically and they are the three most similar and closely related species. Furthermore, no character displacement in acoustic characters between sympatric species of genus Cicada is recorded (Seabra et al., 2008).

Summing up, the present morphometric analyses revealed that divergence in morphology is much less pronounced than the divergence in acoustic signals and DNA. Thus, the congruence between the morphological

TABLE 9. Descriptive statistics for the measurements (in $\mathrm{mm}$ ) of seven structures of the male genitalia of thespecies of Cicada studied.

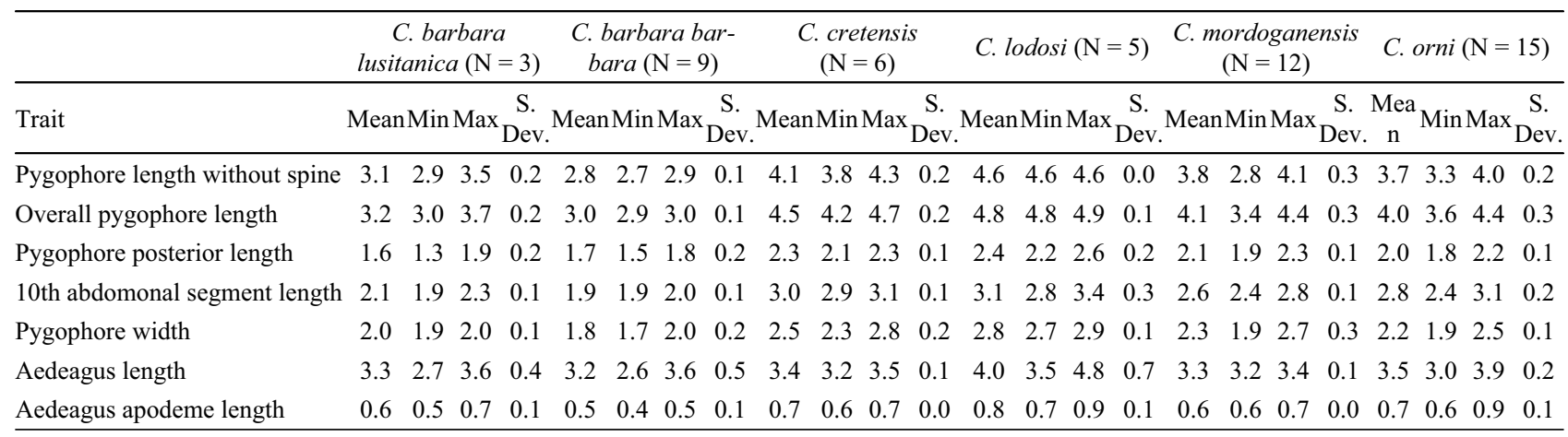


TABLE 10. Factor loadings of the principal component analysis (PCA) based on a correlation matrix of the seven measurements made on structures of male genitalia of the species of Cicada studied.

\begin{tabular}{lcc}
\hline & Component 1 & Component 2 \\
\hline Pygophore length without spine & -0.953 & 0.112 \\
Overall pygophore length & -0.980 & -0.042 \\
Pygophore posterior length & -0.897 & -0.216 \\
$10^{\text {th }}$ abdominal segment length & -0.940 & 0.030 \\
Pygophore width & -0.856 & 0.090 \\
Aedeagus length & -0.415 & 0.791 \\
Aedeagus apodeme length & -0.610 & 0.068 \\
\hline
\end{tabular}

divergence in external structures, and either behavioural (acoustic) or genetic divergence is quite low.

ACKNOWLEDGEMENTS. We are grateful to all colleagues who helped us in the field and in other ways, namely G. PintoJuma, S. Seabra, G. André, J. Sueur, S. Puissant, S. Drosopoulos and I. Kandemir. Appreciation is also due to M. Boulard for loan of cicada material. We also thank the reviewers whose comments and criticisms improved the presentation of this paper. The study was financially supported in part by Centre for Environmental Biology (Faculty of Science, University of Lisbon).

\section{REFERENCES}

Boulard M. \& Mondon B. 1995: Vies et mémoires de cigales. Équinoxe, Barbentane, $159 \mathrm{pp}$.

Claridge M.F. 1985: Acoustic signals in the Homoptera. Behaviour, taxonomy, and evolution. Annu. Rev. Entomol. 30: 297-317.

Claridge M.F., Dawah H.A. \& Wilson M.R. 1997: Species in insect herbivores and parasitoids - sibling species, host races and biotypes. In Claridge M.F., Dawah M.R. \& Wilson MR (eds): Species: The Units of Biodiversity. Chapman \& Hall, London, pp. 247-272.

Dyтнам C. 2003: Choosing and Using Statistics, a Biologist's Guide. 2nd ed. Blackwell Science, Oxford, xiii +248 pp.

Gogala M. \& TriLAR T. 2004: Bioacoustic investigations and taxonomic considerations on the Cicadetta montana species complex (Homoptera: Cicadoidea: Tibicinidae). Anais Acad. Bras. Ciênc. 76: 316-324.

Gogala M., Drosopoulos S. \& Trilar T. 2008: Cicadetta montana complex (Hemiptera, Cicadidae) in Greece - a new species and new records based on bioacoustics. Dt. Entomol. Z. 55: $91-100$.

Hertach T. 2007: Three species instead of only one: distribution and ecology of the Cicadetta montana species complex (Hemiptera: Cicadoidea) in Switzerland. Bull. Soc. Entomol. Suisse 80: 37-61.

Paterson H.E.H. 1985: The recognition concept of species. In Vrba E.S. (ed.): Species and Speciation. Transvaal Museum Monograph no. 4, Pretoria, pp. 21-29.

Pinto-Juma G., Simões P.C., Seabra S. \& Quartau J.A. 2005: Calling song structure and geographic variation in Cicada orni Linnaeus (Hemiptera: Cicadidae). Zool. Stud. 44: 81-94.
Pinto-Juma G.A., Quartau J.A. \& Bruford M.W. 2009: Mitochondrial DNA variation and the evolutionary history of the Mediterranean species of Cicada L. (Hemiptera, Cicadoidea). Zool. J. Linn. Soc. 155: 266-288.

Quartau J.A. 1988: A numerical taxonomic analysis of interpecific morphological differences in two closely related species of Cicada (Homoptera, Cicadidae) in Portugal. Great Basin Nat. Mem. 12: 171-181.

Quartau J.A. 1995: Cigarras, esses insectos quase desconhecidos. Correio da Natureza 19: 33-38.

Quartau J.A. \& Simões P. 2003: Bioacoustic and morphological differentiation in two allopatric species of the genus Tibicina Amyot (Hemiptera, Cicadoidea) in Portugal. Dt. Entomol. Z. 50: 113-119.

Quartau J.A. \& Simões P.C. 2006: Acoustic evolutionary divergence in cicadas: the species of Cicada L. in southern Europe. In Drosopoulos S. \& Claridge M.F. (eds): Insect Sounds and Communication: Physiology, Behaviour, Ecology and Evolution. Taylor and Francis, Boca Raton, pp. 227-237.

Quartau J.A., Ribeiro M., Simões P.C. \& Crespo A. 2000: Taxonomic separation by isozyme electrophoresis of two closely related species of Cicada L. (Hemiptera: Cicadoidea) in Portugal. J. Nat. Hist. 34: 1677-1684.

Quartau J.A., Ribeiro M., Simões P.C. \& Coelho M.M. 2001: Genetic divergence among populations of two closely related species of Cicada Linnaeus (Hemiptera: Cicadoidea) in Portugal. Insect Syst. Evol. 31: 99-106.

Seabra S., Simões P.C., Drosopoulos S. \& Quartau J.A. 2000: Genetic variability and differentiation in two allopatric species of the genus Cicada L. (Hemiptera: Cicadoidea) in Greece. Dt. Entomol. Z. 47: 143-145.

Seabra S.G., André G. \& Quartau J.A. 2008: Variation in the acoustic properties of the calling songs of Cicada barbara and C. orni (Hemiptera: Cicadidae) at the individual and populational levels. Zool. Stud. 47: 1-10.

Simon C. 1992: Discriminant analysis of year classes of periodical cicada based on wing morphometric data enhanced by molecular information. In Sorensen J.T. \& Footit R.G. (eds): Ordinations in the Study of Morphology, Evolution and Systematics of Insects: Applications and Quantitative Genetic Rationales. Elsevier, Amsterdam, pp. 309-323.

Simões P.C., Boulard M.M., Rebelo M.T., Drosopoulos S., Claridge M.F., Morgan J.C. \& Quartau J.A. 2000: Differences in the male calling songs of two sibling species of Cicada (Hemiptera: Cicadoidea) in Greece. Eur. J. Entomol. 97: $437-440$.

Sueur J. \& Aubin T. 2003: Specificity of cicada calling songs in the genus Tibicina (Hemiptera: Cicadidae). Syst. Entomol. 28: 481-492.

Sueur J. \& Puissant S. 2007: Similar look but different song: a new Cicadetta species in the montana complex (Insecta, Hemiptera, Cicadidae). Zootaxa 1442: 55-68.

Sueur J., Puissant S., Simões P.C., Seabra S., Boulard M. \& Quartau J.A. 2004: Cicadas from Portugal: revised list of species with eco-ethological data (Hemiptera: Cicadidae). Insect Syst. Evol. 35: 177-187.

Received September 24, 2008; revised and accepted April 16, 2009 